\title{
On the applicability of multiaxial high cycle fatigue criteria to metallic materials
}

\author{
Roberta A. Gonçalves ${ }^{1}$, Marcos V. Pereira ${ }^{1, *}$ and Fathi A. Darwish ${ }^{2}$ \\ ${ }^{1}$ Catholic University of Rio de Janeiro, Department of Chemical and Materials Engineering, Rua Marques de São Vicente 225, 22453- \\ 901 Rio de Janeiro - RJ, Brazil. \\ ${ }^{2}$ Fluminense Federal University, Department of Civil Engineering, Rua Passo da Patria 156, 24210-240 Niteroi - RJ, Brazil.
}

\begin{abstract}
A comparative study is made of the applicability of critical plane based multiaxial high cycle fatigue models to predicting the fatigue behavior of metallic materials. A number of models, namely Matake, McDiarmid, Carpinteri and Spagnoli, Liu and Mahadevan and Papadopoulos, were applied to fatigue limit states, involving synchronous fully reversed in-phase sinusoidal bend and torsion loading. The results obtained indicated a good predictive capability of the models with an average error index situated approximately between $-5,5 \%$ and $4,5 \%$. However, this average was limited to less than $3 \%$ for the latter three models. Finally, the critical plane orientation, which, for a given material, is characteristic of the proper model, is compared with that of the fracture plane, exclusively determined by the ratio between the shear stress and normal stress amplitudes.
\end{abstract}

\section{Introduction}

High cycle fatigue under uniaxial loading has shown that many metallic materials possess a fatigue limit, which means that they can sustain a very high (theoretically infinite) number of cycles without fatigue failure. However, many mechanical components, such as railroad wheels, crankshafts, axles and turbine blades are expected to experience multiaxial loading during their in-service lifetime. Accordinglly, the fatigue problem becomes more complex due to the complexity of the stress states, loading histories and different orientations of the initial crack in the components.

Generalization of the fatigue limit concept for multiaxial loading conditions is considered compatible with the idea of dividing the whole stress space in two parts, namely safe and unsafe. The safe part, which contains the origin, is bounded by a closed surface and the fatigue criterion can thus be expressed in terms of an inequality whose satisfaction signifies that the stress state induced by the external cyclic loading remains within the safe part of the stress space [].

Over many decades of research, a large number of models have been proposed to predict fatigue failure under multiaxial loading conditions. As the stress levels involved in high cycle fatigue are kept below the elastic limit, only stress based models, namely Matake (Ma) [1], McDiarmid (Mc) [2,3], Findley (F) [4], Carpinteri and Spagnole (C \& S) [5-7], Liu and Mahadevan (L \& M) [8] and Papadopoulos (P) [9,10] models, are to be considered in the present work. The underlying purpose is to test the applicability of these six models to some experimental loading conditions, available in the

Corresponding author: marcospe $@$ puc-rio.br literature $[11,12]$, involving synchronous fully reversed sinusoidal in-phase bend and torsion loading applied to a variety of metallic materials with different fatigue behaviors. At this point, it should be emphasized that all of the chosen loading conditions correspond to the fatigue limit state above which fatigue occurs and below which fatigue life extends over a very high number of cycles, in analogy with the fatigue limit state for uniaxial loading.

Whereas the use of Papadopoulos criterion requires only knowing the applied stress amplitudes, the other models depend for their application on the prior identification of the critical plane, where fatigue damage can occur leading to crack nucleation. Assuming that the critical plane is already known, the normal and shear stress amplitudes can be determined and fatigue failure assessment can thus be presented in the form of inequality. The relative difference between the two sides of the inequality is referred to as the error index and, for a given fatigue limit state, it can be null, positive or negative. As the fatigue criteria in question are to be applied simultaneously to a given loading condition, a comparison of the error index involved is expected to provide a good assessment of their predictive capabilities in defining the fatigue behavior.

Finally, the critical plane orientation, determined for each model, is presented in comparison with that of the fracture plane, for the loading conditions involved.

\section{High cycle multiaxial fatigue criteria}

The inequalities representative of the Matake, McDiamird, Findley, Carpinteri and Spangnoli, Liu and 
Mahadevan and Papadopoulos are given, respectively, by expressions (1) to (6):

$$
\begin{gathered}
C_{a}+\mu N_{\max } \leq t_{-1} \\
C_{a}+\frac{t_{-1}}{2 \sigma_{u}} N_{\max } \leq t_{-1} \\
C_{a}+k N_{\max } \leq f \\
\sqrt{\left.\frac{N_{\text {max }}^{2}+\left(\frac{f_{-1}}{t_{-1}}\right)^{2} C_{a}^{2}}{N_{a}+\left(1+\eta \frac{N_{m}}{f_{-1}}\right)}\right]_{-1}^{2}+\left(\frac{C_{a}}{t_{-1}}\right)^{2}} \leq \lambda \\
\sqrt{\frac{f_{-1}}{3}+\tau_{a}^{2}+\alpha \frac{\sigma_{a}+\sigma_{m}}{3}} \leq t_{-1}
\end{gathered}
$$

$C_{a}$ and $N_{\max }$, in the expressions above, are, respectively, the shear stress amplitude and the maximum normal stress acting on the critical plane. $N_{\max }$ is given by

$$
N_{\text {max }}=N_{a}+N_{m}
$$

where $N_{a}$ is the amplitude and $N_{m}$ the mean value.

The constants $\mu, k, f, \eta, \lambda$ and $\alpha$ are material parameters, which depend exclusively, as shown in Table 1, on the fatigue limits for fully reversed bending $f_{-1}$ and fully reversed torsion $t_{-1}$. Applying the McDiamird criterion, one needs to know, in the addition to $t_{-1}$, the ultimate tensile strength $\sigma_{u}$.

Different from the critical plane approach, the Papadopoulos criterion is applied by simply substituting the applied normal stress and shear stress amplitudes $\sigma_{a}$ and $\tau_{a}$, together with the mean stress $\sigma_{\mathrm{m}}$ in expression (6). However, one should note that this type of criterion, which is based on the mesoscopic scale approach, is valid for the category of hard metals where the ratio $t_{-1} / f_{-1}$ lies between $1 / \sqrt{3}$ and 0,8 [9].

For fully reserved loading, which is the type of loading considered in the present work, $\sigma_{m}$ and $N_{m}$ are

\begin{tabular}{|c|}
\hline$\mu=2\left(\frac{t_{-1}}{f_{-1}}\right)-1$ \\
\hline$k=\frac{2-\left(\frac{f_{-1}}{t_{-1}}\right)}{2 \sqrt{\frac{f_{-1}}{t_{-1}}-1}}$ \\
\hline$f=\sqrt{\frac{f_{-1}^{2}}{4\left(\frac{f_{-1}}{t_{-1}}-1\right)}}$ \\
\hline$\eta=\frac{3}{4}+\frac{1}{4}\left(\frac{\sqrt{3}-\frac{f_{-1}}{t_{-1}}}{\sqrt{3}-1}\right)$ \\
\hline$\lambda=\left[\cos ^{2}(2 \delta) s^{2}+\sin ^{2}(2 \delta)\right]^{1 / 2}$ \\
\hline$\alpha=\frac{t_{-1}-\left(\frac{f_{-1}}{\sqrt{3}}\right)}{\frac{f_{-1}}{3}}$ \\
\hline
\end{tabular}
taken to be null and consequently $N_{\max }$ is to be replaced by $N_{a}$ and hence inequalities (5) and (6) simplify to

$$
\begin{aligned}
& \sqrt{\left(\frac{N_{a}}{f_{-1}}\right)^{2}+\left(\frac{C_{a}}{t_{-1}}\right)^{2}} \leq \lambda \\
& \sqrt{\frac{\sigma_{a}^{2}}{3}+\tau_{a}^{2}+\alpha \frac{\sigma_{a}}{3}} \leq t_{-1}
\end{aligned}
$$

Table 1. Definition of the pertinent material constants.

where $s=t_{-1} / f_{-1}$.

\section{Critical plane identification}

This can be achieved by first considering a general material plane oriented at angle $\psi$ (Fig.1), where the stress amplitudes $N_{a}$ and $C_{a}$ acting on such a plane due to applied synchronous in-phase sinusoidal bending and torsion are given by

$$
\begin{gathered}
N_{a}=\frac{1}{2} \sigma_{a}+\frac{1}{2} \sigma_{a} \cos 2 \psi+\tau_{a} \sin 2 \psi \\
C_{a}=\left|\frac{1}{2} \sigma_{a} \sin 2 \psi-\tau_{a} \cos 2 \psi\right|
\end{gathered}
$$

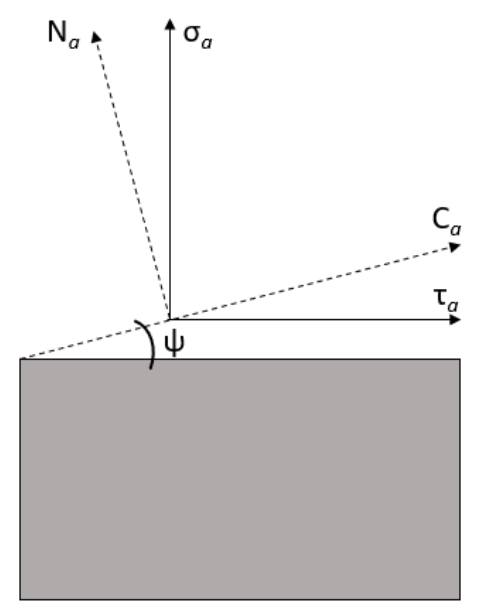

Figure 1: Schematic representation of normal and shear stress amplitudes acting on an arbitrary plane defined by the angle $\psi$. 
Both the Matake and McDiarmid models refer to the critical plane as the plane on which, the shear stress amplitude $C_{a}$ reaches its maximum. Accordingly the angle $\psi_{c}$ that defines the critical plane orientation is given by

$$
\tan \psi_{c}=-\frac{\sigma_{a}}{2 \tau_{a}}
$$

and the corresponding $N_{a}$ and $C_{a}$ values can be calculated and then substituted in the left hand side (LHS) of inequalities (1) and (2).

In regard to the Findley model, the critical plane is defined by maximizing the linear combination $\left(C_{a}+\right.$ $k N_{a}$ ) and $\psi_{c}$ in this case will be given by

$$
\tan 2 \psi_{c}=\frac{\sigma_{a}+2 k \tau_{a}}{k \sigma_{a}-2 \tau_{a}}
$$

Again with $\psi_{c}$ already known, $N_{a}$ and $C_{a}$ can be calculated and the LHS of inequality (3) can be determined.

Identification of the critical plane for both C\&S and L\&M models depend, in the first place, on determining the fracture plane orientation. For a given loading history, the fatigue fracture plane is identified as the material plane normal to the maximum principal stress [5,8]. For a fully reversed loading, the fracture plane is thus oriented at an angle $\psi_{f}$ given by

$$
\tan 2 \psi_{f}=\frac{-2 \tau_{a}}{\sigma_{a}}
$$

Knowing $\psi_{f}, \psi_{c}$ is expressed as $[5,8]$

$$
\psi_{c}=\psi_{f}+\delta
$$

where $\delta$ is given by [5]

$$
\delta=\left[1-\left(\frac{t_{-1}}{f_{-1}}\right)^{2}\right] \frac{3 \pi}{8}
$$

for C\&S model.

$$
\delta=\frac{1}{2} \cos ^{-1}(A)
$$

for L\&M model

where $\mathrm{A}=\left[\frac{-2+\sqrt{4-4\left(\frac{1}{s^{2}}-1\right)\left(5-\frac{1}{s^{2}}-4 s^{2}\right)}}{2\left(5-\frac{1}{s^{2}}-4 s^{2}\right)}\right]$

Now, with the angle $\psi_{c}$ already known, one can proceed to apply the C\&S and L\&M model, substituting $N_{a}$ and $C_{a}$ in the LHS of their respective inequalities.

\section{Results and discussion}

The fracture plane and critical plane orientations, defined by the angle $\psi_{f}$, and $\psi_{c}$ are listed in Tables 2 and 3 , in

\begin{tabular}{|c|c|c|c|c|c|}
\hline \multirow[b]{2}{*}{$\sigma_{a}(\mathbf{M P a})$} & \multirow[b]{2}{*}{$\tau_{a}(\mathbf{M P a})$} & \multirow[b]{2}{*}{$\psi_{\mathrm{f}}\left({ }^{\circ}\right)$} & \multicolumn{3}{|c|}{$\psi_{\mathrm{c}}\left(^{\circ}\right)$} \\
\hline & & & Ma & Mc & $\mathbf{F}$ \\
\hline \multicolumn{6}{|c|}{ Material: Hard steel: $f_{-1}=313.9$ MPa; } \\
\hline \multicolumn{6}{|c|}{$\mathrm{t}_{-1}=196.2 \mathrm{MPa} ; \sigma_{\mathrm{u}}=704.1 \mathrm{MPa}$} \\
\hline 327.7 & $\mathbf{0 . 0}$ & 0.0 & 45.0 & 45.0 & 37.8 \\
\hline 308.0 & 63.9 & 11.3 & 56.3 & 56.3 & 49.0 \\
\hline 255.1 & 127.5 & 22.5 & 67.5 & 67.5 & 60.3 \\
\hline 141.9 & 171.3 & 33.8 & 78.8 & 78.8 & 71.5 \\
\hline 0.0 & 201.1 & 45.0 & 0.0 & 0.0 & 7.2 \\
\hline
\end{tabular}
terms of $\sigma_{a}$ and $\tau_{a}$, for the variety of materials indicated in the tables.

Table 2. Fracture and critical plane orientations for different materials, under in phase bend and torsion stresses for $\mathrm{Ma}, \mathrm{Mc}$ and $\mathrm{F}$ models.

Material: Hard steel: $\mathbf{f}_{-1}=313.9 \mathrm{MPa}$;

$\mathrm{t}_{-1}=196.2 \mathrm{MPa} ; \sigma_{\mathrm{u}}=680.0 \mathrm{MPa}$

\begin{tabular}{cc|c|ccc|}
$\mathbf{1 3 8 . 1}$ & $\mathbf{1 6 7 . 1}$ & 33.8 & 168.8 & 168.8 & 176.0 \\
$\mathbf{2 4 5 . 3}$ & $\mathbf{1 2 2 . 6 5}$ & 22.5 & 157.5 & 157.5 & 164.7 \\
$\mathbf{2 9 9 . 1}$ & $\mathbf{6 2 . 8}$ & 11.4 & 146.4 & 146.4 & 153.6 \\
\hline
\end{tabular}

Material: 42CrMo4: $\mathrm{f}_{-1}=398.0 \mathrm{MPa}$;

$\mathbf{t}_{-1}=260.0 \mathrm{MPa} ; \sigma_{\mathrm{u}}=1025.0 \mathrm{MPa}$

\begin{tabular}{ll|l|lll|}
$\mathbf{3 2 8 . 0}$ & $\mathbf{1 5 7 . 0}$ & 21.9 & 156.9 & 156.9 & 165.8 \\
$\mathbf{2 3 3 . 0}$ & $\mathbf{2 2 4 . 0}$ & 31.3 & 166.3 & 166.3 & 175.2 \\
\hline
\end{tabular}

Material: 34Cr4: $\mathrm{f}_{-1}=410.0 \mathrm{MPa}$;

$\mathrm{t}_{-1}=256.0 \mathrm{MPa} ; \sigma_{\mathrm{u}}=795.0 \mathrm{MPa}$

\begin{tabular}{ll|l|lll}
$\mathbf{3 1 4 . 0}$ & $\mathbf{1 5 7 . 0}$ & 22.5 & 67.5 & 67.5 & 60.3 \\
\hline
\end{tabular}

Material: 30NCD16: $\mathrm{f}_{-1}=660.0 \mathrm{MPa}$;

$\mathrm{t}_{-1}=410.0 \mathrm{MPa} ; \sigma_{\mathrm{u}}=1880.0 \mathrm{MPa}$

\begin{tabular}{ll|l|lll|}
$\mathbf{4 8 5 . 0}$ & $\mathbf{2 8 0 . 0}$ & 24.6 & 69.6 & 69.6 & 62.5 \\
\hline
\end{tabular}

Material: Mild steel: $\mathrm{f}_{-1}=\mathbf{2 3 5 . 4} \mathrm{MPa}$;

$\mathbf{t}_{-1}=137.3 \mathrm{MPa} ; \sigma_{\mathrm{u}}=518.8 \mathrm{MPa}$

\begin{tabular}{cc|r|rrr}
$\mathbf{2 4 5 . 3}$ & $\mathbf{0 . 0}$ & 0.0 & 45.0 & 45.0 & 40.2 \\
$\mathbf{2 3 5 . 6}$ & $\mathbf{4 8 . 9}$ & 11.3 & 146.3 & 146.3 & 51.5 \\
$\mathbf{1 8 7 . 3}$ & $\mathbf{9 3 . 6}$ & 22.5 & 157.5 & 157.5 & 62.7 \\
$\mathbf{1 0 1 . 3}$ & $\mathbf{1 2 2 . 3}$ & 33.8 & 168.8 & 168.8 & 74.0 \\
$\mathbf{0 . 0}$ & $\mathbf{1 4 2 . 3}$ & 45.0 & 0.0 & 0.0 & 4.8 \\
\hline
\end{tabular}

Material: Cast iron: $\mathrm{f}_{-1}=96,1 \mathrm{MPa}$;

$\mathrm{t}_{-1}=91,2 \mathrm{MPa} ; \sigma_{\mathrm{u}}=230.0 \mathrm{MPa}$

\begin{tabular}{cc|r|rrr}
$\mathbf{9 3 . 2}$ & $\mathbf{0 . 0}$ & 0.0 & 45.0 & 45.0 & 13.1 \\
$\mathbf{9 5 . 2}$ & $\mathbf{1 9 . 7}$ & 11.2 & 56.2 & 56.2 & 24.3 \\
$\mathbf{8 3 . 4}$ & $\mathbf{4 1 . 6}$ & 22.5 & 157.5 & 157.5 & 9.4 \\
$\mathbf{5 6 . 3}$ & $\mathbf{6 8 . 0}$ & 33.8 & 168.8 & 168.8 & 20.7 \\
$\mathbf{0 . 0}$ & $\mathbf{9 4 . 2}$ & 45.0 & 0.0 & 0.0 & 31.9 \\
\hline
\end{tabular}


Table 3. Fracture and critical plane orientations for different materials, under in phase bend and torsion stresses for C\&S and L\&M models.

\begin{tabular}{|c|c|c|c|c|}
\hline & & & & $\left({ }^{\circ}\right)$ \\
\hline$\sigma_{a}(\mathrm{MPa})$ & $\tau_{a}(\mathrm{MPa})$ & $\psi_{\mathrm{f}}\left(^{\circ}\right)$ & C\&S & L\&M \\
\hline Material: & Hard steel & $f_{-1}=31$ & $3.9 \mathrm{MI}$ & \\
\hline $\mathbf{t}_{-1}=196$ & МPa; $\sigma_{u}=$ & $704.1 \mathrm{~N}$ & IPa & \\
\hline 327.7 & 0.0 & 0.0 & 41.1 & 39.2 \\
\hline 308.0 & 63.9 & 11.3 & 52.4 & 50.5 \\
\hline 255.1 & 127.5 & 22.5 & 63.6 & 61.7 \\
\hline 141.9 & 171.3 & 33.8 & 74.9 & 73.0 \\
\hline 0.0 & 201.1 & 45.0 & 86.1 & 84.2 \\
\hline $\begin{array}{l}\text { Material: } \\
t_{-1}=196.2\end{array}$ & $\begin{array}{l}\text { Hard stee } \\
\text { МРa; } \sigma_{u}=\end{array}$ & $\begin{array}{l}f_{-1}=31 \\
680.0 M\end{array}$ & $\begin{array}{l}3.9 \mathrm{MI} \\
\mathrm{Pa}\end{array}$ & \\
\hline 138.1 & 167.1 & 33.8 & 74.9 & 73.0 \\
\hline 245.3 & 122.65 & 22.5 & 63.6 & 61.7 \\
\hline 299.1 & 62.8 & 11.4 & 52.5 & 50.6 \\
\hline Material: & 12CrMo4 & $1=398$ & 0 MP & \\
\hline$t_{-1}=260$ & МРa; $\sigma_{u}$ & 1025.0 & MPa & \\
\hline 328.0 & 157.0 & 21.9 & 60.6 & 58.5 \\
\hline 233.0 & 224.0 & 31.3 & 70.0 & 67.9 \\
\hline Material: & 34Cr4: $f_{-1}$ & $410.0 \mathrm{I}$ & МРa; & \\
\hline$t_{-1}=256$ & МРа; $\sigma$ & 795.0 & МPa & \\
\hline 314.0 & 157.0 & 22.5 & 63.7 & 61.7 \\
\hline Material: & 30NCD16 & $f_{-1}=660$ & $.0 \mathrm{MP}$ & \\
\hline$t_{-1}=410.0$ & МРa; $\sigma_{\mathrm{u}}$ & 880.0 & MPa & \\
\hline 485.0 & 280.0 & 24.6 & 66.0 & 64.2 \\
\hline Material: & Mild stee & $f_{-1}=23$ & $.4 \mathrm{MP}$ & \\
\hline $\mathbf{t}_{-1}=137$. & ИРa; $\sigma_{\mathrm{u}}$ & $518.8 \mathrm{~N}$ & IPa & \\
\hline 245.3 & 0.0 & 0.0 & 44.5 & 44.1 \\
\hline 235.6 & 48.9 & 11.3 & 55.8 & 55.4 \\
\hline 187.3 & 93.6 & 22.5 & 67.0 & 66.6 \\
\hline 101.3 & 122.3 & 33.8 & 78.3 & 77.9 \\
\hline 0.0 & 142.3 & 45.0 & 89.5 & 89.1 \\
\hline Material: & ast iron & $-1=96$ & МPa & \\
\hline $\mathrm{t}_{-1}=91$ & $\mathrm{~Pa} ; \sigma_{\mathrm{u}}$ & $0.0 \mathrm{~N}$ & & \\
\hline 93.2 & 0.0 & 0.0 & 6.7 & 16.3 \\
\hline 95.2 & 19.7 & 11.2 & 17.9 & 27.5 \\
\hline 83.4 & 41.6 & 22.5 & 29.2 & 38.8 \\
\hline 56.3 & 68.0 & 33.8 & 40.5 & 50.1 \\
\hline 0.0 & 94.2 & 45.0 & 51.7 & 61.3 \\
\hline
\end{tabular}

The angle $\psi_{f}$, which is invariably determined by the stress amplitudes, is in fact unique for all the models. As can be observed from the same table, the higher the ratio $\tau_{a} / \sigma_{a}$, the higher the angle $\psi_{f}$, consistent with the fact that $\psi_{f}$ tends to zero for uniaxial normal stress and to $45^{\circ}$ for pure shear loading.
As one may expect, the critical plane orientation, defined by the angle $\psi_{c}$ in table, varies from one model to another. Except for the Matake and McDiamird criteria, where the critical plane orientation has the same value of $\psi_{c}$, considerable differences can be observed among the other models. These differences are also seen to vary appreciably with the stress amplitudes as well as with the fatigue properties of the material. However, in view of their proper formulation, the C\&S and L\&M criteria result in essentially the same critical plane orientations, except for a few number of loading conditions associated with the experimental testing of cast iron.

The error index I, associated with the application of any of the six models, refers to the relative difference between the two sides of the inequality. I can thus be expressed as

$$
I=\frac{L H S-R H S}{R H S} \times 100
$$

The values of I corresponding to the different loading conditions are listed in Tables 4 and 5, for the variety of materials involved.

Except for a few cases, the vast majority of the I values are situated within the range $-10 \%$ to $10 \%$, indicating a good predictive capability of the criteria in question. This is also demonstrated by Fig.2, where the overall average values of I are also shown. One can thus conclude that, except for the McDiarmid model, the others are moderately conservative, with the C\&S, L\&M and $\mathrm{P}$ models exhibiting the lowest error compared to the other three.

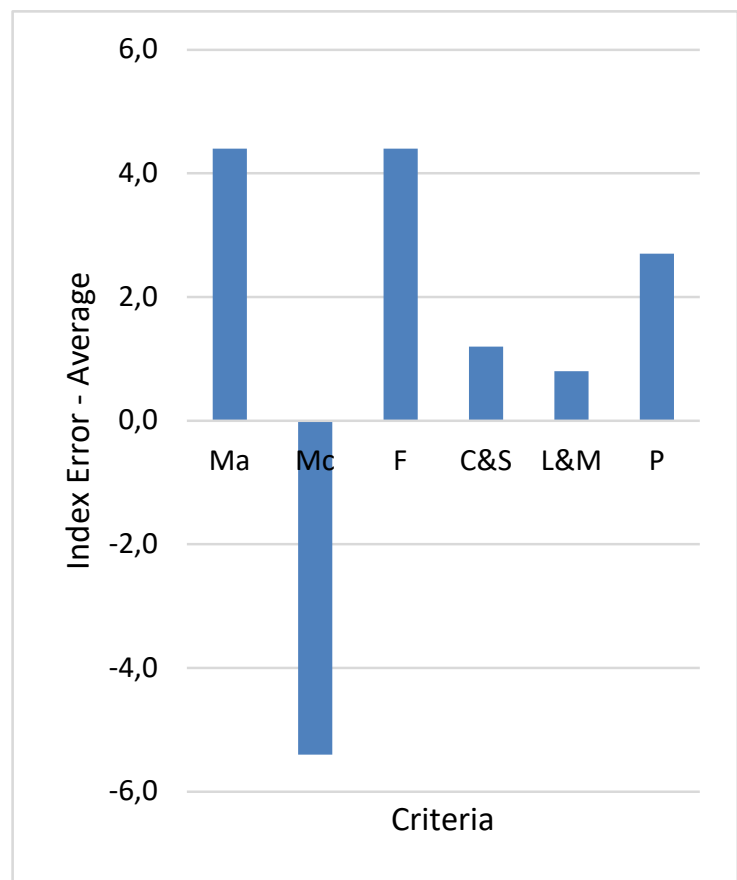

Figure 2: Comparative presentation of the average value of the error index, for the fatigue criteria in question. 
Table 4: Error index, corresponding $\mathrm{Ma}, \mathrm{Mc}$ and $\mathrm{F}$ criteria

\begin{tabular}{|c|c|c|c|c|}
\hline \multirow[b]{2}{*}{$\sigma_{a}(\mathrm{MPa})$} & \multirow[b]{2}{*}{$\tau_{a}(\mathbf{M P a})$} & \multicolumn{3}{|c|}{ Index Error - I (\%) } \\
\hline & & Ma & Mc & $\mathbf{F}$ \\
\hline \multicolumn{5}{|c|}{$\begin{array}{l}\text { Material: Hard steel: } f_{-1}=313.9 \mathrm{MPa} \\
t_{-1}=196.2 \mathrm{MPa} ; \sigma_{u}=704.1 \mathrm{MPa}\end{array}$} \\
\hline 327.7 & $\mathbf{0 . 0}$ & 4.4 & -4.8 & 4.4 \\
\hline 308.0 & 63.9 & 4.6 & -4.1 & 4.6 \\
\hline 255.1 & 127.5 & 8.2 & 1.0 & 2 \\
\hline 141.9 & 171.3 & 3.6 & -0.4 & 3.5 \\
\hline 0.0 & 201.1 & 2.5 & 2.5 & 2.5 \\
\hline
\end{tabular}

Material: Hard steel: $f_{-1}=313.9$ MPa; $\mathrm{t}_{-1}=196.2 \mathrm{MPa} ; \sigma_{\mathrm{u}}=680.0 \mathrm{MPa}$

\begin{tabular}{cc|ccc}
$\mathbf{1 3 8 . 1}$ & $\mathbf{1 6 7 . 1}$ & 1.0 & -2.8 & 0.9 \\
$\mathbf{2 4 5 . 3}$ & $\mathbf{1 2 2 . 6 5}$ & 4.0 & -2.6 & 4.0 \\
$\mathbf{2 9 9 . 1}$ & $\mathbf{6 2 . 8}$ & 1.7 & -6.3 & 1.7 \\
\hline
\end{tabular}

Material: 42CrMo4: $\mathrm{f}_{-1}=398.0 \mathrm{MPa}$;

$\mathrm{t}_{-1}=260.0 \mathrm{MPa} ; \sigma_{\mathrm{u}}=1025.0 \mathrm{MPa}$

\begin{tabular}{rr|rrr|}
$\mathbf{3 2 8 . 0}$ & $\mathbf{1 5 7 . 0}$ & 6.8 & -4.7 & 6.7 \\
$\mathbf{2 3 3 . 0}$ & $\mathbf{2 2 4 . 0}$ & 10.9 & 2.8 & 10.8 \\
\hline
\end{tabular}

Material: 34Cr4: $f_{-1}=410.0 \mathrm{MPa}$;

$\mathrm{t}_{-1}=256.0 \mathrm{MPa} ; \sigma_{\mathrm{u}}=795.0 \mathrm{MPa}$

\begin{tabular}{ll|lll}
314.0 & 157.0 & 2.0 & -3.4 & 2.0 \\
\hline
\end{tabular}

Material: 30NCD16: $\mathrm{f}_{-1}=660.0 \mathrm{MPa}$;

$t_{-1}=410.0 \mathrm{MPa} ; \sigma_{u}=1880.0 \mathrm{MPa}$

\begin{tabular}{ll|ll}
485.0 & $\mathbf{2 8 0 . 0}$ & 4.7 & -3.2
\end{tabular}

Material: Mild steel: $\mathrm{f}_{-1}=235.4 \mathrm{MPa}$; $\mathrm{t}_{-1}=137.3 \mathrm{MPa} ; \sigma_{\mathrm{u}}=518.8 \mathrm{MPa}$

\begin{tabular}{cc|ccc}
$\mathbf{2 4 5 . 3}$ & $\mathbf{0 . 0}$ & 4.2 & 1.1 & 4.2 \\
$\mathbf{2 3 5 . 6}$ & $\mathbf{4 8 . 9}$ & 7.2 & 4.3 & 7.2 \\
$\mathbf{1 8 7 . 3}$ & $\mathbf{9 3 . 6}$ & 7.8 & 5.5 & 7.8 \\
$\mathbf{1 0 1 . 3}$ & $\mathbf{1 2 2 . 3}$ & 2.6 & 1.3 & 2.5 \\
$\mathbf{0 . 0}$ & $\mathbf{1 4 2 . 3}$ & 3.6 & 3.6 & 3.6 \\
\hline
\end{tabular}

Material: Cast iron: $\mathrm{f}_{-1}=\mathbf{9 6 , 1} \mathrm{MPa}$; $\mathrm{t}_{-1}=91,2 \mathrm{MPa} ; \sigma_{\mathrm{u}}=230.0 \mathrm{MPa}$

\begin{tabular}{ll|lll}
93.2 & 0.0 & -3.0 & -38.7 & -3.0
\end{tabular}

\begin{tabular}{ll|lll}
95.2 & 19.7 & 3.4 & -33.1 & 3.4
\end{tabular}

\begin{tabular}{ll|lll}
83.4 & 41.6 & 5.6 & -26.3 & 5.6
\end{tabular}

\begin{tabular}{ll|lll}
$\mathbf{5 6} .3$ & $\mathbf{6 8 . 0}$ & 8.5 & -13.2 & 8.4
\end{tabular}

\begin{tabular}{ll|lll}
$\mathbf{0 . 0}$ & 94.2 & 3.3 & 3.3 & 3.3
\end{tabular}

Table 5: Error index, corresponding C\&S, L\&M and P criteria.

\begin{tabular}{|c|c|c|c|c|}
\hline \multirow[b]{2}{*}{$\sigma_{a}(\mathrm{MPa})$} & \multirow[b]{2}{*}{$\tau_{a}(\mathrm{MPa})$} & \multicolumn{3}{|c|}{ Index Error - I $(\%)$} \\
\hline & & & L\&M & \\
\hline \multicolumn{5}{|c|}{$\begin{array}{l}\text { Material: Hard steel: } f_{-1}=313.9 \mathrm{MPa} \\
t-1=196.2 \mathrm{MPa} ; \sigma u=704.1 \mathrm{MPa}\end{array}$} \\
\hline 327. & 00 & 1.8 & 4.3 & \\
\hline 308 & 6 & 1.2 & 3. & \\
\hline 255.1 & 127.5 & 3.1 & 5.3 & \\
\hline 141.9 & 171.3 & -1.5 & 0.3 & \\
\hline 0.0 & 201.1 & 1.9 & 2.3 & \\
\hline
\end{tabular}

Material: Hard steel: $f_{-1}=313.9 \mathrm{MPa}$;

$\mathrm{t}-1=196.2 \mathrm{MPa} ; \sigma \mathrm{u}=680.0 \mathrm{MPa}$

\begin{tabular}{lc|rrr}
$\mathbf{1 3 8 . 1}$ & $\mathbf{1 6 7 . 1}$ & -3.9 & -2.8 & -2.3 \\
$\mathbf{2 4 5 . 3}$ & $\mathbf{1 2 2 . 6 5}$ & -0.8 & 1.3 & 1.4 \\
$\mathbf{2 9 9 . 1}$ & $\mathbf{6 2 . 8}$ & -1.5 & 0.3 & 0.9 \\
\hline
\end{tabular}

Material: 42CrMo4: $\mathrm{f}_{-1}=398.0 \mathrm{MPa}$;

$\mathrm{t}-1=260.0 \mathrm{MPa} ; \sigma \mathrm{u}=1025.0 \mathrm{MPa}$

\begin{tabular}{ll|lll}
$\mathbf{3 2 8 . 0}$ & $\mathbf{1 5 7 . 0}$ & 0.7 & 4.5 & 4.2 \\
$\mathbf{2 3 3 . 0}$ & $\mathbf{2 2 4 . 0}$ & 4.1 & 6.6 & 7.3 \\
\hline
\end{tabular}

Material: 34Cr4: $\mathrm{f}_{-1}=410.0 \mathrm{MPa}$;

$\mathrm{t}-1=256.0 \mathrm{MPa} ; \sigma \mathrm{u}=795.0 \mathrm{MPa}$

\begin{tabular}{ll|lll}
314.0 & $\mathbf{1 5 7 . 0}$ & -2.8 & -0.8 & -0.5 \\
\hline
\end{tabular}

Material: 30NCD16: $f_{-1}=660.0 \mathrm{MPa}$;

$\mathrm{t}-1=410.0 \mathrm{MPa} ; \sigma \mathrm{u}=1880.0 \mathrm{MPa}$

\begin{tabular}{ll|lll}
$\mathbf{4 8 5 . 0}$ & $\mathbf{2 8 0 . 0}$ & -0.3 & 1.1 & 1.8
\end{tabular}

Material: Mild steel: $\mathrm{f}_{-1}=235.4 \mathrm{MPa}$;

t-1 = 137.3 MPa; $\sigma u=518.8 \mathrm{MPa}$

\begin{tabular}{cc|rrr}
$\mathbf{2 4 5 . 3}$ & $\mathbf{0 . 0}$ & 3.9 & 4.0 & 4.1 \\
$\mathbf{2 3 5 . 6}$ & $\mathbf{4 8 . 9}$ & 5.9 & 6.0 & 6.3 \\
$\mathbf{1 8 7 . 3}$ & $\mathbf{9 3 . 6}$ & 4.7 & 5.0 & 5.0 \\
$\mathbf{1 0 1 . 3}$ & $\mathbf{1 2 2 . 3}$ & -1.0 & -1.0 & -0.8 \\
$\mathbf{0 . 0}$ & $\mathbf{1 4 2 . 3}$ & 3.6 & 4.0 & 3.6 \\
\hline
\end{tabular}

Material: Cast iron: $\mathrm{f}_{-1}=96,1 \mathrm{MPa}$;

t-1 = 91,2 MPa; $\sigma \mathrm{u}=230.0 \mathrm{MPa}$

\begin{tabular}{cc|rrr}
$\mathbf{9 3 . 2}$ & $\mathbf{0 . 0}$ & -3.6 & -13.9 & -3.0 \\
$\mathbf{9 5 . 2}$ & $\mathbf{1 9 . 7}$ & 2.5 & -26.3 & 2.8 \\
$\mathbf{8 3 . 4}$ & $\mathbf{4 1 . 6}$ & 4.0 & 4.8 & 3.8 \\
$\mathbf{5 6 . 3}$ & $\mathbf{6 8 . 0}$ & 5.4 & 6.8 & 5.9 \\
$\mathbf{0 . 0}$ & $\mathbf{9 4 . 2}$ & -1.7 & 2.7 & 3.3 \\
\hline
\end{tabular}




\section{Conclusion}

Based on what is presented above, the following conclusions can be drawn

- Fracture plane orientation, in fully reversed multiaxial fatigue loading, is exclusively determined by the ratio between the shear and normal stress amplitudes.

- For a given loading condition, the critical plane orientation depends on the adapted multiaxial fatigue criterion. Whereas the Matake and McDiarmid models possess the same critical plane, the C\&S and L\&M models indicate critical planes with orientations that are close to each other.

- Critical plane orientation predicted by the Findley criterion is generally close to that defined by the Matake model.

- The overall average of the error index I is limited to $-5,5 \% \leq \mathrm{I} \leq 4,5 \%$, indicating reasonable predictive capability of the models in question in defining fatigue behavior.

- Except for the McDiarmid criterion, the models are seen to be conservative as they mostly exhibit positive I values.

This work was developed within the scope of the Research and Technological Development of the Brazilian Electric Energy Sector Program regulated by ANEEL, with the support of the Eneva Companies - Pecém II Energy Generation S.A., Itaqui Energy Generation S.A. and Paranaíba I, II and III Energy Generation S.A.

\section{References}

1. T. Matake, An explanation on fatigue limit under combined stress, Bull JSME 20, 257 (1977)

2. DL. McDiamid, Fatigue under out of phase bending and torsion, Fat. Fract. Engng. Mater. Struct 9, 457 (1987)

3. DL. Mc Diarmid, A general criterion for high cycle multiaxial fatigue failure, Fat. Fract. Engng. Mater. Struct 14, 429 (1991)

4. WN. Findley, A theory for the effect of mean stress on fatigue of metals under combined torsion and axial load or bending, J. Engng. Ind. Trans. ASME 81, 301 (1959) (Cited in reference 5)

5. A. Carpinteri, A. Spagnoli, Multiaxial high-cycle fatigue criterion for hard metals, Int. J. Fat. 23, 135 (2001)

6. A. Carpinteri, A. Spagnoli, S. Vantadori, Multiaxial fatigue assessment using simplified critical planebased criterion, Int. J. Fat. 33, 969 (2011)

7. A. Carpinteri, A. Spagnoli, S. Vantadori, C. Bagnic, Structural integrity assessment of metallic components under multiaxial fatigue: the $C-S$ criterion and its evolution, Fat. Fract. Engng. Mater. Struct 36, 870 (2013)

8. Y. Liu, S. Mahadevan, Multiaxial high-cycle fatigue criterion and life prediction for metals, Int. J. Fat. 27, 870 (2005)

9. IV. Papadopoulos, P. Davoli, C. Gorla, M. Fillipini, A. Bernarconi, A comparative study of multiaxial high-cycle fatigue criteria for metals, Int. J. Fat. 19, 219 (1997)

10. IV. Papadopoulos, Long life fatigue under multiaxial loading, Int. J. Fat. 23, 839 (2001)

11. T. Nishihara, M. Kawamoto, The strength of metals under combined alternating bending and torsion with phase difference, Mem College Eng., Kyoto Imper. Univ. 11, 85 (1945) (Reported in reference 5)

12. H. Zenner, R. Heindenreich, IZ. Richter Werkstofftech, 16, 101 (1985) (Reported in reference 9) 